\title{
Composição arquitetônica e percepção estética: 12 projetos de arquitetos premiados com 0 Pritzker
}

\author{
Architectural composition and aesthetic perception: 12 \\ projects by architects awarded with the Pritzker
}

\section{Antônio Tarcísio da Luz Reis}

\section{Resumo}

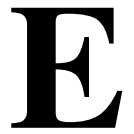

ste artigo tem como objetivo a avaliação estética da composição arquitetônica de 12 projetos de arquitetos que receberam o maior prêmio de arquitetura existente no mundo, o Pritzker de Arquitetura, de 1983 a 2012, a identificação dos projetos mais e menos preferidos e das justificativas para tais preferências, por pessoas com diferentes níveis e tipos de formação educacional. A coleta de dados foi realizada através de questionário disponibilizado on-line no programa LimeSurvey a três grupos, em um total de 220 respondentes, conforme segue: arquitetos (65); não arquitetos com curso universitário (134); e pessoas sem conclusão e sem início de curso universitário (21). Cada um dos 12 projetos foi representado no questionário por uma fotografia colorida editada, visando à retirada de elementos que poderiam afetar a avaliação estética das edificações. Testes estatísticos não paramétricos, como Kendall's W e Kruskal-Wallis, foram utilizados para a análise dos dados. Os resultados evidenciam, por exemplo, que os projetos de arquitetos que receberam o Prêmio Pritzker são percebidos diferentemente em função, fundamentalmente, de seus diferentes níveis de ordem e de estímulo visual, embora exista maior valorização da presença de ordem nas composições por parte dos respondentes arquitetos e maior consideração da existência de estímulo visual por parte dos não arquitetos.

Palavras-chave: Composição arquitetônica. Percepção estética. Prêmio Pritzker de Arquitetura.

\begin{abstract}
This aim of this paper is to present an aesthetic evaluation of the architectural composition of 12 projects by architects awarded the world's most prestigious architecture prize, the Pritzker Architecture Prize, from 1983 to 2012, the identification of the most and least preferred projects and the justifications for such preferences by people with different levels and types of education. The data collection was performed through an online questionnaire in the LimeSurvey program aimed at three groups, totalling 220 respondents, as follows: architects (65); non-architect college graduates (134); persons without a college education (21). Each of the 12 projects was represented in the questionnaire by an edited colour photograph, aiming at removing elements that might affect the aesthetic evaluation of the buildings. Nonparametric statistical tests, such as the Kendall's W and the KruskalWallis tests, were used for data analysis. The results show, for example, that the projects designed by recipients of the Pritzker Prize were perceived differently due basically to their different levels of order and visual stimulus, even though there was greater appreciation of the presence of order in the compositions by the respondents who are architects and greater consideration of the existence of visual stimulus by non-architects.
\end{abstract}

Keywords: Architectural composition. Aesthetic perception, Pritzker Architecture Prize. 


\section{Introdução}

Composição arquitetônica diz respeito aos elementos que fazem parte de uma edificação e às suas relações (REIS; BIAVATTI; PEREIRA, 2014) e pode "[...] ser vista como a arte de balancear partes arquitetônicas individuais dentro de todo um conjunto de uma edificação [...]" (HASSE; WEBER, 2010, p. 1). Decorre que uma composição arquitetônica pode ser avaliada com base na estética empírica, fundamentada na teoria positiva, na procura de explicações através de afirmações que podem ser testadas através de métodos científicos (LANG, 1987); assim, a estética empírica trata da compreensão das razões que justificam as avaliações estéticas, assumindo que diferentes pessoas podem ter reações estéticas idênticas ou similares para determinada composição arquitetônica (REIS; BIAVATTI; PEREIRA, 2011). A estética empírica faz parte da percepção ambiental ou da área de estudos ambiente-comportamento, que procura compreender e explicar as relações entre as pessoas e o ambiente construído e, assim, também possibilitar o projeto de edificações que atendam, em suas várias dimensões, às necessidades das pessoas (REIS; LAY, 2006).

Como a composição arquitetônica envolve relações visuais, a estética formal - parte da estética empírica que trata da estrutura das formas (NASAR, 1994) - fornece a fundamentação necessária para tais avaliações ao considerar o processo de percepção visual, que possibilita que as pessoas tendam a perceber similarmente uma mesma composição em função dos estímulos visuais serem percebidos independentemente de experiência prévia e de valores (WEBER, 1995). Ainda que a estética simbólica - parte da estética empírica que trata do conteúdo das formas (NASAR, 1994) - também possa explicar avaliações estéticas com base nas associações estabelecidas com os elementos existentes na composição, possibilitadas pelo processo de cognição, as avaliações estéticas tendem a ser explicadas, principalmente, pela estética formal (REIS; BIAVATTI; PEREIRA, 2011, 2014; REIS; SOUZA, 2016). Nesse sentido, Redies (2007) já argumentava que não é o conteúdo semântico, mas o estímulo gerado pela forma que determina o componente estético da percepção visual. Portanto, a percepção estética, assim como a avaliação estética, estão, principalmente, relacionadas à percepção visual que responde por mais de $80 \%$ de nossa interação com o ambiente construído (PORTEOUS, 1996).

Logo, a percepção e a avaliação estética baseadas na estética formal tornam-se importantes para aferir a qualidade estética de um projeto arquitetônico, incluindo os projetos dos arquitetos que receberam o Prêmio Pritzker de Arquitetura. Esse é o maior prêmio de arquitetura existente, também referenciado por alguns como "o Prêmio Nobel da Arquitetura" e "a honra mais alta da profissão", devido à sua importância mundial, e foi instituído em 1979 pela 'Hyatt Foundation', dirigida pela família Pritzker de Chicago. Esta premiação visa, anualmente, em uma cerimônia realizada em um local com valor arquitetônico: honrar um ou mais arquitetos vivos que tenham contribuído, de forma significativa e consistente para a humanidade e o ambiente construído, através de projetos executados que evidenciem talento, visão e comprometimento (THE HYATT..., 2018). O Prêmio Pritzker é atribuído por um júri independente composto por cinco a nove profissionais reconhecidos nas áreas da arquitetura, educação, publicações, cultura e negócios, que permanecem por períodos diferentes de maneira a possibilitar um equilíbrio entre os que continuam e os novos membros (THE HYATT..., 2018), com a quantidade de arquitetos tendendo a ser equivalente a de jurados de outras áreas (MAHDAVINEJAD; HOSSEINI, 2019).

Conforme a análise dos conteúdos das citações dos jurados realizada por Mahdavinejad e Hosseini (2019), verifica-se que a atenção à forma no trabalho dos arquitetos premiados sempre esteve presente em tais citações, que tendem a incluir termos tais como:

(a) único, original, etc. (a partir de 1989);

(b) icônico, figurativo, escultural (de 2001 a 2009); e

(c) equilíbrio, harmonia, combinação (de 2010 a 2015).

Ainda, tem sido mencionada a relação da obra com a região ou sua internacionalidade, com o passado e o futuro, com o contexto, ambiente, contexto social e cultural, e com paisagem, a escala da obra, seus materiais e tecnologia. Particularmente, os arquitetos premiados de 2003 a 2007 foram elogiados por serem icônicos, pelas formas arrojadas e figurativas (MAHDAVINEJAD; HOSSEINI, 2019). A beleza dos projetos também é um dos aspectos incluídos em suas avaliações pelos júris, uma vez que na atribuição do Prêmio Pritzker também são considerados os princípios fundamentais da arquitetura por Vitruvius, nomeadamente venustas (beleza), firmitas (firmeza/estrutura) e utilitas (utilitário/função) (MAHDAVINEJAD; HOSSEINI, 2019). Contudo, tende a predominar nas citações termos que remetem mais à estética simbólica do que à estética formal, não aparecendo em tais citações referências específicas à composição arquitetônica, às relações formais entre os elementos constituintes de tais projetos, às ideias de 
ordem e estímulo. Essas ideias têm sido recorrentemente indicadas para justificar avaliações estéticas positivas de edificações e conjuntos de edificações (ver, por exemplo, Reis, Biavatti e Pereira $(2011,2014)$ ).

Ainda, embora os termos "atenção às necessidades do cliente", "projetar com clientes", "clientes dos arquitetos" tenham sido usados nas citações do júri desde 2000 (MAHDAVINEJAD; HOSSEINI, 2019, p. 83), não são mencionadas referências à estética dos projetos percebida pelos clientes e/ou usuários. Nesse sentido, Gifford et al. (2000) já haviam destacado a importância do entendimento das percepções dos clientes por parte dos arquitetos, e que a falta de tal entendimento pode resultar em incompatibilidades graves entre as preferências do designer e leigo.

Adicionalmente, não são encontradas pesquisas que tratem de avaliações estéticas de projetos de arquitetos que receberam o Prêmio Pritzker, tanto por parte de arquitetos quanto por parte de não arquitetos. No tocante a esse ponto, têm sido encontradas diferenças entre as preferências de arquitetos e leigos com formação, em relação a edificações com diferentes estilos (FAWCETT; ELLINGHAM; PLATT, 2008). As explicações para tais diferenças estariam nas distintas formações de arquitetos e leigos (GIFFORD et al., 2000). Por sua vez, em estudo realizado por Jeffrey e Reynolds (1999), embora as preferências por fachadas fossem similares entre os arquitetos e distintas daquelas mais convergentes de planejadores e leigos, algumas fachadas eram fortemente apreciadas ou depreciadas por qualquer um desses três grupos. Em consonância com esse fato, outros estudos revelam que quando as ideias de ordem e estímulo visual estão claramente presentes, em uma edificação ou em um conjunto de edificações, não existem diferenças significativas entre as avaliações estéticas de tais edificações por arquitetos, não arquitetos com formação universitária e pessoas sem formação universitária (REIS; BIAVATTI; PEREIRA, 2011, 2014). Assim, existe a necessidade de novas pesquisas que tratem de avaliações estéticas de projetos de arquitetos que receberam o Prêmio Pritzker, através de pessoas com diferentes níveis e tipos de formação educacional.

Portanto, este artigo tem como objetivo a avaliação estética da composição arquitetônica de 12 projetos de arquitetos premiados com o Pritzker de Arquitetura, de 1983 a 2012, a identificação dos projetos mais e menos preferidos e das justificativas para tais preferências, por arquitetos, não arquitetos com formação universitária e pessoas sem formação universitária.

\section{Metodologia}

Uma vez que essa investigação se insere na área de estudos ambiente-comportamento, especificamente na estética empírica, são utilizados métodos das ciências sociais para analisar e avaliar a qualidade estética dos projetos (LAY; REIS, 2005). Para atender os objetivos deste artigo, foram selecionados 12 projetos de arquitetos premiados com o Pritzker de 1983 a 2012 (Figuras 3 a 10). Esses projetos fazem parte de uma pesquisa envolvendo 27 projetos selecionados a partir de 587 projetos de arquitetos premiados com o Pritzker no período de 1979 a 2012 (identificados na página do Prêmio Pritzker, nos sites dos próprios arquitetos, e alguns em livros e revistas). Com base em pré-testes envolvendo o próprio pesquisador e estudantes de arquitetura, esses projetos foram categorizados em bonitos, intermediários e feios, visando à inclusão e à comparação na pesquisa de projetos representativos dessas três categorias. Assim, os 12 projetos foram organizados em quatro conjuntos de três projetos, com cada projeto pertencendo a uma destas três categorias, nomeadamente:

(a) conjunto 1 - Figura 3 (Museu de arte por Álvaro Siza - bonito; Hotel por Jean Nouvel - feio; Cemitério por Aldo Rossi - intermediário);

(b) conjunto 2 - Figura 5 (Biblioteca por Gordon Bunshaft - intermediário; Estádio de futebol por Herzog e De Meuron - bonito; Ginásio de esportes por Fumihiko Maki (1993) - feio);

(c) conjunto 3 - Figura 7 (Ginásio esportivo por Kenzo Tange - feio; Prefeitura de Dallas por I. M. Pei intermediário; Café por Wang Shu - bonito); e

(d) conjunto 4 - Figura 9 (Ópera de Sydney por Jorn Utzon - bonito; Biblioteca e museu por Gordon Bunshaft - intermediário; Centro de imprensa por Kenzo Tange - feio).

Cada um desses projetos foi representado em um questionário por uma fotografia colorida, incluída em cada conjunto conforme sorteio e ordenadas no questionário pelos pesquisadores de maneira a evitar a repetição de uma categoria na mesma posição nos diferentes conjuntos. O critério para a seleção das fotografias está na representação dos atributos formais dos 12 projetos de forma a possibilitar as avaliações estéticas. As 12 fotografias foram editadas no programa Photoshop CS3, visando à retirada de elementos que poderiam afetar a avaliação estética das edificações, tais como diferentes céus, pisos e entornos. A fotografia colorida tem 
sido utilizada em vários estudos envolvendo avaliações estéticas de edificações e sua adequação para simular visualmente a realidade tem sido evidenciada (GREGOLETTO, 2019; REIS; BIAVATTI; PEREIRA, 2011, 2014; SANOFF, 1991).

O questionário foi disponibilizado on-line no programa LimeSurvey a três grupos com diferentes níveis e tipos de formação educacional, em um total de 220 respondentes, conforme segue:

(a) arquitetos (65; professores de cursos de arquitetura - UFRGS, PUC, UNIRITTER e UPF; mestrandos/doutorandos - PROPUR; ex-orientandos de Trabalho de Conclusão de Curso - TCC);

(b) não arquitetos com curso universitário [134; funcionários e professores de diversas escolas/faculdades da UFRGS (Administração; Educação Física; Fisioterapia e Dança; Enfermagem; Engenharia;

Biblioteconomia e Comunicação; Ciências Econômicas; Educação; Farmácia; Odontologia) com formação universitária distinta de arquitetura, design, artes visuais e publicidade e propaganda]; e

(c) pessoas sem conclusão e nem início de curso universitário (21; servidores ou técnico-administrativos da UFRGS).

Essas quantidades podem variar entre diferentes questões sobre as avaliações e preferências pelos projetos, já que nem todas foram preenchidas por todos os respondentes. Instruções iniciais indicavam a necessidade de enquadramento em um desses três grupos para poder responder o questionário assim como procedimentos no preenchimento, tais como a possibilidade de retornar para questões anteriores, de interromper o questionário e retomar em outro momento, no mesmo ou em outro computador, seguindo passos especificados.

Cada projeto foi avaliado individualmente (Figura 1) por meio de questões de escolha simples elaboradas pelo autor e já utilizadas de forma similar em outras pesquisas (REIS; BIAVATTI; PEREIRA, 2011, 2014), tal como "Avalie a aparência do edifício 1: ( ) muito bonito; ( ) bonito; ( ) nem bonito, nem feio; ( ) feio; ( ) muito feio". Adicionalmente, o projeto foi comparado com os outros dois projetos em cada conjunto visando a indicação do mais (Figura 2) e do menos preferido, em questões de escolha simples do tipo "Indique o edifício mais preferido quanto à aparência: ( ) Edifício 1; ( ) Edifício 2; ( ) Edifício 3". Ainda, foram selecionadas pelos respondentes as razões para as preferências em questões de múltipla escolha tal como "Indique as razões para o edifício mais preferido: ( ) Similaridade entre as formas; ( ) Falta de similaridade entre as formas; ( ) Relação ordenada entre as formas; ( ) Relação desordenada entre as formas; ( ) Regularidade geométrica das formas; ( ) Falta de regularidade geométrica das formas; ( ) Existência de estímulo visual; ( ) Falta de estímulo visual; ( ) Outros: ............. Essas categorias indicam as relações formais entre os elementos constituintes da composição arquitetônica dos projetos, a existência ou não das ideias de ordem e estímulo, tendo sido utilizadas em outros estudos envolvendo avaliações estéticas de edificações (REIS; BIAVATTI; PEREIRA, 2011, 2014).

A alternativa "Outros" foi utilizada para possibilitar que o respondente também mencionasse uma razão não incluída na questão de múltipla escolha. Neste artigo são mencionadas as razões indicadas por, pelo menos, $25 \%$ dos respondentes em cada grupo que selecionaram determinado projeto como o mais ou o menos preferido quanto à aparência, em cada um dos quatro conjuntos com três projetos cada um.

Figura 1 - Tela de computador com questão relativa à avaliação da aparência do edifício

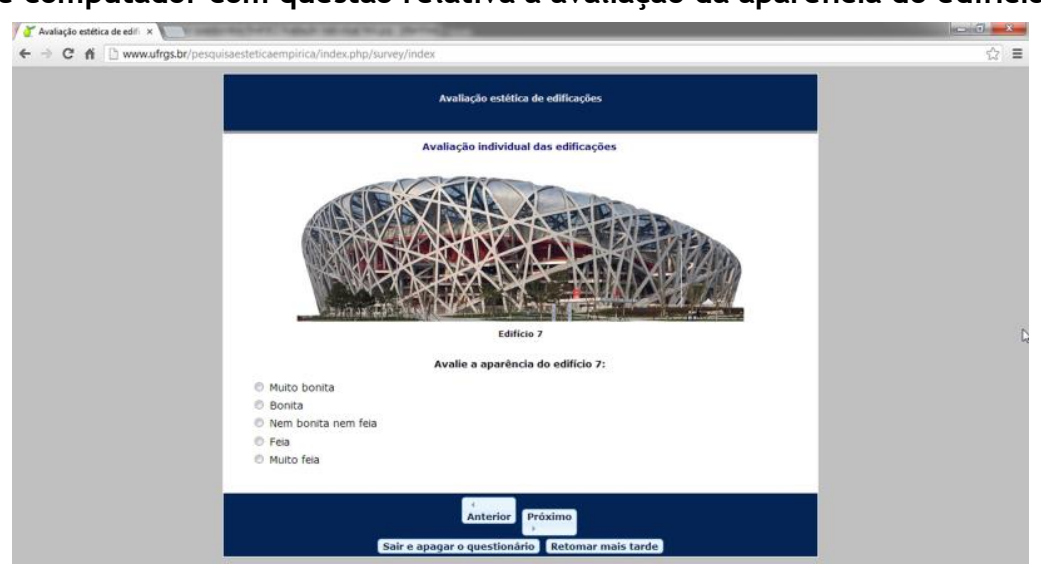


Figura 2 - Tela de computador com questão relativa à indicação do edifício mais preferido quanto à aparência

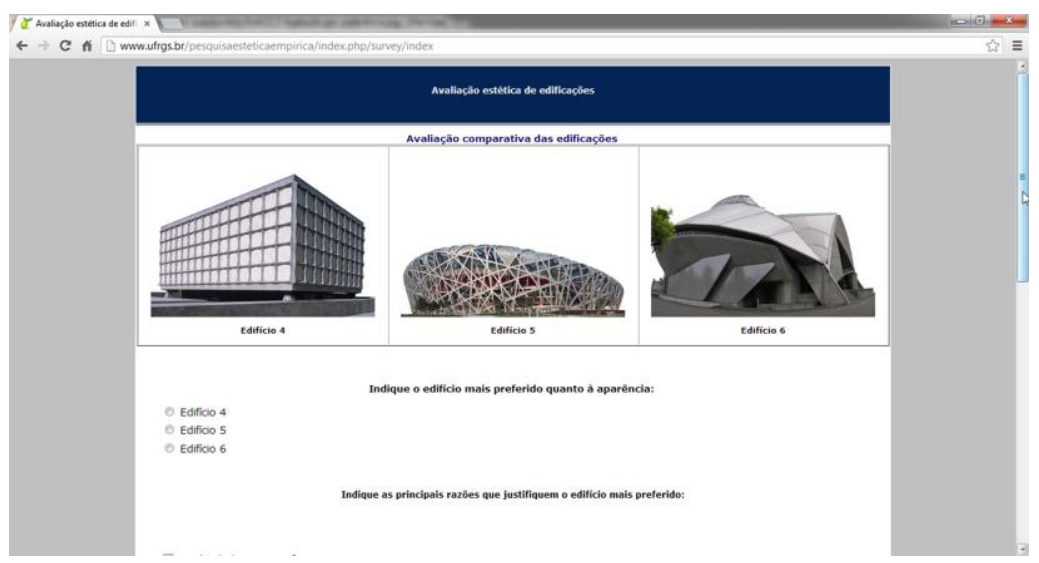

Os dados foram analisados por meio dos testes estatísticos não paramétricos Kendall's W e Kruskal-Wallis no programa PASW Statistics. O teste Kendall's W foi realizado para identificar a existência de diferenças estatisticamente significativas entre as avaliações das aparências dos três projetos em um conjunto por um grupo de respondentes. Por sua vez, o teste Kruskal-Wallis foi utilizado para identificar a existência de diferenças estatisticamente significativas entre as avaliações da aparência de um mesmo projeto pelos três grupos de respondentes (LAY; REIS, 2005). Ainda, nos casos em que o teste Kruskal-Wallis revelou a existência de diferenças estatisticamente significativas entre as avaliações (sig. $<$ ou $=0,05$ ), foi realizado o teste post-hoc de comparações múltiplas de Dunn, baseado nas medianas, visando à identificação da existência de diferenças estatisticamente entre as avaliações de cada dois dos três grupos de respondentes.

\section{Resultados}

Considerando o conjunto 1 com os projetos de Álvaro Siza, Jean Nouvel e Aldo Rossi (Figura 3), o projeto de Álvaro Siza é claramente o mais preferido pelos arquitetos $(86,7 \%$ - 52 de 60$)$, fundamentalmente devido à:

(a) existência de estímulo visual (31 - 59,6\%); e

(b) relação ordenada entre as formas $(25-48,1 \%)$.

Esse projeto também é o mais satisfatório e sua avaliação pelos arquitetos foi muito positiva $(80 \%-52$ de 65; Figura 4). O menos preferido pelos arquitetos $(55 \%$ - 33 de 60$)$ é o projeto de Jean Nouvel, devido à relação desordenada entre as formas $(11-33,3 \%)$, ao excesso de estímulos/muitos elementos $(9-27,3 \%)$, e, especificamente, às cores utilizadas $(9-27,3 \%)$, consideradas, por exemplo, como excessivas. O projeto de Aldo Rossi também foi o menos preferido por uma quantidade não desprezível de arquitetos $(40 \%-24$ de $60)$ em função da falta de estímulo visual $(20-83,3 \%)$, e da regularidade geométrica das formas $(9-$ $37,5 \%$ ). O projeto de Jean Nouvel foi o pior avaliado e sua avaliação foi muito negativa $(51,6 \%)$, assim como foi a avaliação do projeto de Aldo Rossi (46,8\%). Essas diferenças entre as avaliações dos projetos nesse primeiro conjunto pelos arquitetos são confirmadas estatisticamente (Kendall's W, teste estatístico = $54,921$, sig. $=0,000)$ e tais avaliações são consistentes com as preferências.

O projeto de Álvaro Siza (Figura 3) é claramente o mais preferido pelos não arquitetos com formação universitária $(63,3 \%$ - 81 de 128$)$, fundamentalmente devido à:

(a) existência de estímulo visual $(40-49,4 \%)$;

(b) relação ordenada entre as formas $(25-30,9 \%)$; e

(c) regularidade geométrica das formas $(22-27,2 \%)$.

Esse projeto também é o mais satisfatório e foi avaliado positivamente pela maioria desses respondentes (54,5\% - 73 de 134; Figura 4). O menos preferido pelos não arquitetos com formação universitária $(72,1 \%$ 93 de 129) é o projeto de Aldo Rossi, devido à:

(a) falta de estímulo visual (66 - 71\%); e 
(b) regularidade geométrica das formas $(35-37,6 \%)$.

Esse projeto também é o menos satisfatório e foi avaliado negativamente por 79\% (105 de 133). Essas diferenças entre as avaliações dos projetos nesse primeiro conjunto pelos não arquitetos com formação universitária são confirmadas estatisticamente (Kendall's W, teste estatístico $=104,464$, sig. $=0,000$ ) e essas avaliações estão em sintonia com as preferências.

O projeto de Álvaro Siza (Figura 3) também é o mais preferido por aqueles sem formação universitária $(55,6 \%$ - 10 de 18$)$, fundamentalmente devido à existência de estímulo visual $(7-70 \%)$ e à relação ordenada entre as formas $(3-30 \%)$. Esse projeto também é o mais satisfatório e foi avaliado positivamente pela maioria desses respondentes $(57,1 \%-12$ de 21 ; Figura 4). O projeto de Jean Nouvel foi o preferido por uma quantidade um pouco menor desses respondentes (44,4\% - 8 de 18$)$, em função da:

(a) existência de estímulo visual $(8-100 \%)$;

(b) regularidade geométrica das formas $(5-62,5 \%)$;

(c) similaridade entre as formas $(3-37,5 \%)$; e

(d) relação ordenada entre as formas $(3-37,5 \%)$.

O menos preferido por esses respondentes (72,2\% - 13 de 18) é o projeto de Aldo Rossi, devido à falta de estímulo visual $(11-84,6 \%)$, regularidade geométrica das formas $(4-30,8 \%)$, e relação ordenada entre as formas $(4-30,8 \%)$. Esse projeto também é o menos satisfatório e foi avaliado negativamente por $80 \%$ ( 16 de 20). Essas diferenças entre as avaliações dos projetos nesse primeiro conjunto por aqueles sem formação universitária são confirmadas estatisticamente (Kendall's W, teste estatístico $=18,215$, sig. $=0,000$ ) e essas avaliações também são consistentes com as preferências.

Figura 3 - Preferências pelos projetos de Álvaro Siza, Jean Nouvel e Aldo Rossi - conjunto 1

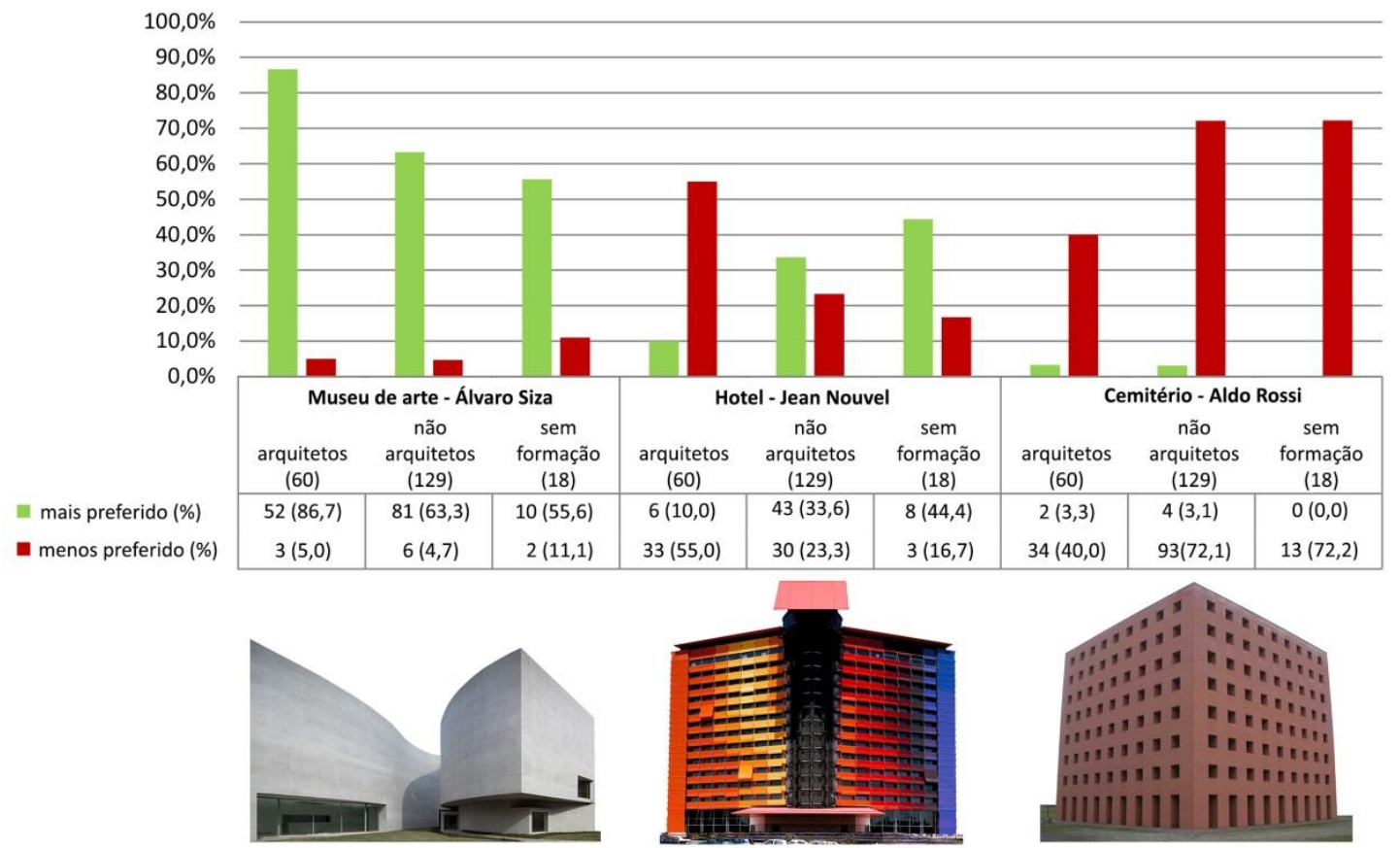

Fontes: 1 - Museu de arte (2009 - construção), Paju-Si, Coréia do Sul, Álvaro Siza (1992 - premiação) http: / / www. architectural-review.com/buildings/mimesis-museum-by-lvaro-siza-carlos-castanheira-and-jun-saung-kimpaju-book-city-south-korea/8607232.article; 2 - Hotel (2005), Madrid, Espanha, Jean Nouvel (2008) http: / / visuall.net/2011/02/23/interesting-hotel-projects-hotel-puerta-america-part-i/; e 3 - Cemitério (1971), Módena, Itália, Aldo Rossi (1990) http://ffffound.com/image/96c856602890d73dcc7a0197b8be8f2e5213f553. 
Por sua vez, as diferenças entre as avaliações do museu de arte de Álvaro Siza, do hotel de Jean Nouvel e do cemitério de Aldo Rossi (Figura 4) pelos três grupos de respondentes são sustentadas estatisticamente (teste Kruskal-Wallis, valores do teste estatístico e significância, respectivamente: 11,648 , sig. = 0,003; 12,055, sig. $=0,002 ; 17,523$, sig. $=0,000)$. O projeto de Álvaro Siza foi mais bem avaliado pelos arquitetos (média dos valores ordinais obtida através do teste Kruskal-Wallis $=$ mvo $=131,82$ ) e pior avaliado pelos não arquitetos com formação universitária $(m v o=100,51)$. Conforme o teste de Dunn, é confirmada a diferença estatisticamente significativa entre as avaliações dos arquitetos e dos não arquitetos (teste estatístico padrão $=9,187$, adj. sig. =0,02). Por outro lado, o projeto de Jean Nouvel foi mais bem avaliado por aqueles sem formação universitária (mvo $=134,55)$ e pior avaliado pelos arquitetos (mvo $=88,80)$. Os resultados do teste de Dunn confirmam a diferença estatisticamente significativa entre as avaliações dos arquitetos e daqueles sem formação universitária (teste estatístico padrão $=-2,964$, adj. sig. $=0,009$ ), assim como entre as avaliações dos arquitetos e dos não arquitetos (teste estatístico padrão $=-2,861$, adj. sig. $=0,013$ ). Por sua vez, o projeto de Aldo Rossi foi mais bem avaliado pelos arquitetos $($ mvo $=134,27)$ e pior avaliado pelos não arquitetos com formação universitária $(m v o=96,30)$, com essa diferença sustentada estatisticamente (teste de Dunn, teste estatístico padrão $=4,176$, adj. sig. $=0,000)$.

Considerando o conjunto 2 com os projetos de Gordon Bunshaft, Herzog e De Meuron e Fumihiko Maki (Figura 5), o projeto de Herzog e De Meuron é claramente o preferido pelos arquitetos (89,8\% - 53 de 59), fundamentalmente devido à existência de estímulo visual $(41-77,4 \%)$ e à relação ordenada entre as formas $(15-28,3 \%)$. Esse projeto também é o mais satisfatório e foi avaliado positivamente pela grande maioria dos arquitetos (80\% - 52 de 65; Figura 6). O menos preferido pelos arquitetos $(62,7 \%-37$ de 59$)$ é o projeto de Fumihiko Maki, devido à relação desordenada entre as formas $(28-75,7 \%)$ e à falta de regularidade geométrica das formas $(17-45,9 \%)$. Esse projeto também foi o pior avaliado, com uma avaliação muito negativa $(66,1 \%$ - 43 de 65). Essas diferenças entre as avaliações dos projetos nesse segundo conjunto pelos arquitetos são confirmadas estatisticamente (Kendall's W, teste estatístico $=72,583$, sig. $=0,000)$ e tais avaliações estão em concordância com as preferências.

O projeto de Herzog e De Meuron (Figura 5) é claramente o mais preferido pelos não arquitetos com formação universitária $(64 \%$ - 80 de 125$)$, fundamentalmente devido à existência de estímulo visual (52 $65 \%)$, mas também devido à percepção por alguns $(20$ - 25\%) da existência de relação desordenada entre as formas. Esse projeto também é o mais satisfatório e foi avaliado positivamente pela maioria desses respondentes $(65,5 \%-87$ de 133; Figura 6). O menos preferido pelos não arquitetos com formação universitária (68,8\% - 86 de 125) é o projeto de Gordon Bunshaft, devido à:

(a) falta de estímulo visual (45 - 52,3\%);

(b) regularidade geométrica das formas $(40-46,5 \%)$;

(c) similaridade entre as formas $(26-30,2 \%)$; e

(d) relação ordenada entre as formas $(23-26,7 \%)$.

Figura 4 - Avaliações individuais dos projetos de Álvaro Siza, Jean Nouvel e Aldo Rossi - conjunto 1

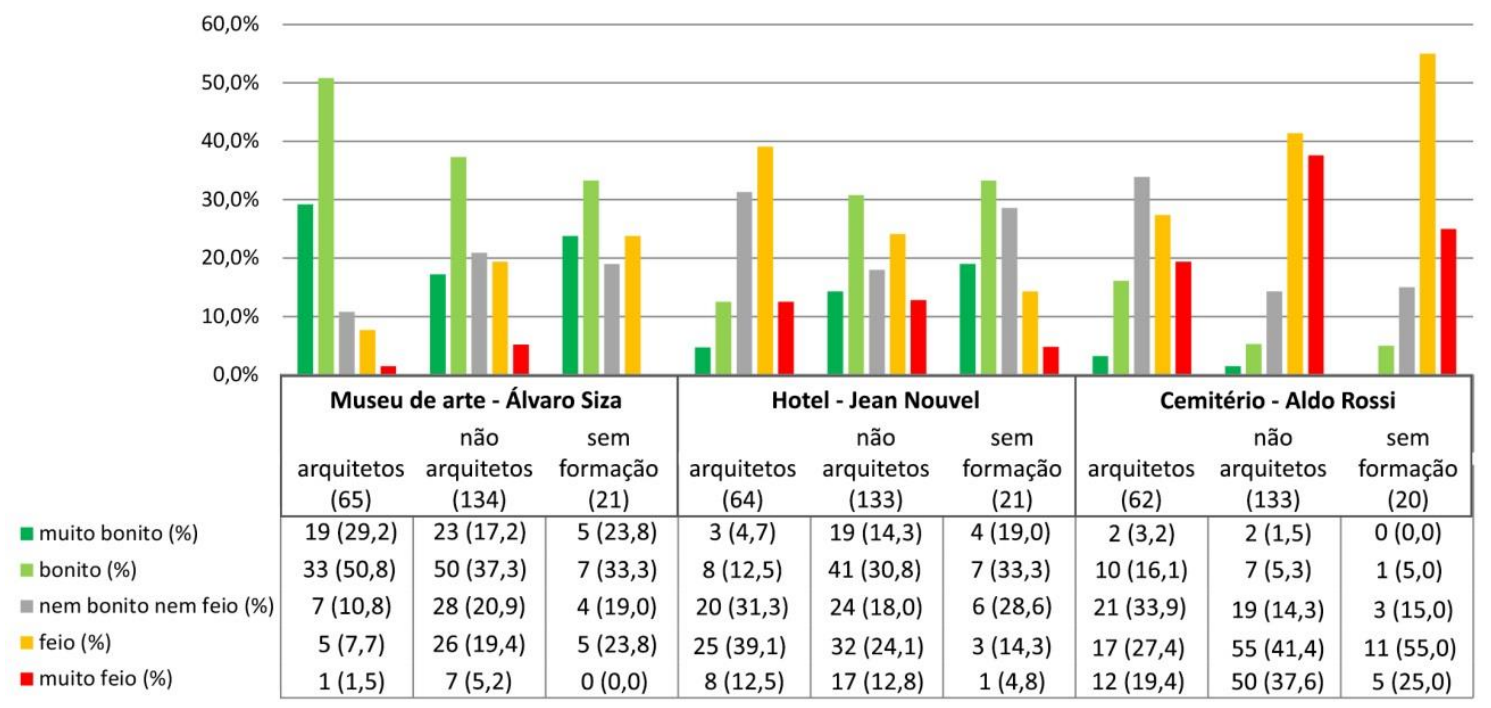


Figura 5 - Preferências pelos projetos de Gordon Bunshaft, Herzog e De Meuron e Fumihiko Maki conjunto 2

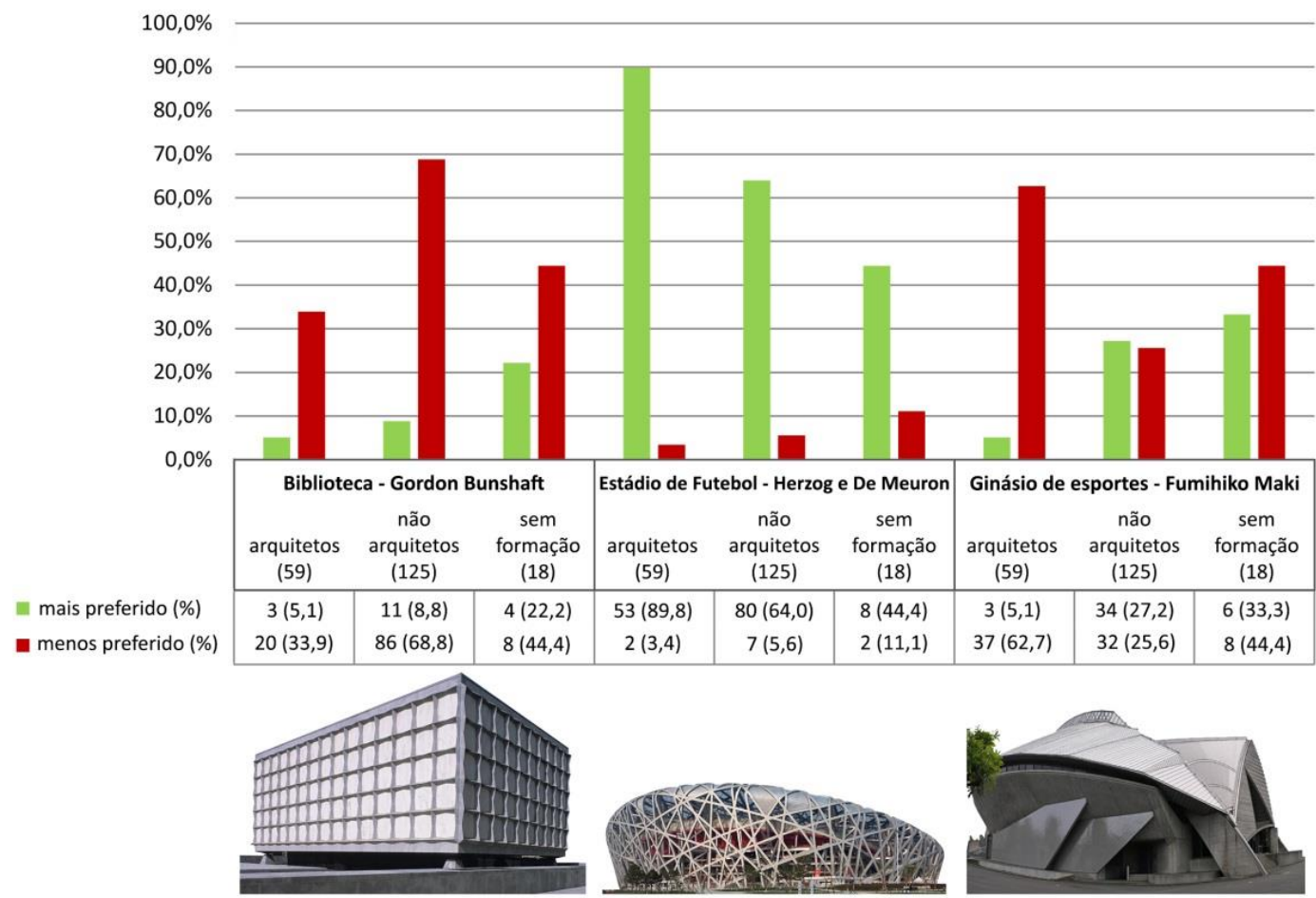

Fontes: 1 - Biblioteca (1963), New Haven, EUA, Gordon Bunshaft (1988) http://larryspeck.com/2010/02/19/beineckerare-book-and-manuscript-library/; 2 - Estádio de futebol (2008), Beijing, China, Herzog e De Meuron (2001) http://www.bustler.net/index.php/article/herzog_de_meurons_birds_nest_wins_riba_lubetkin_prize; e 3 - Ginásio de esportes (1984), Fujisawa, Japão, Fumihiko Maki (1993) http://www.architravel.com/ architravel/building/ fujisawamunicipal-gymnasium.

Figura 6 - Avaliações individuais dos projetos de Gordon Bunshaft, Herzog e De Meuron e Fumihiko Maki - conjunto 2

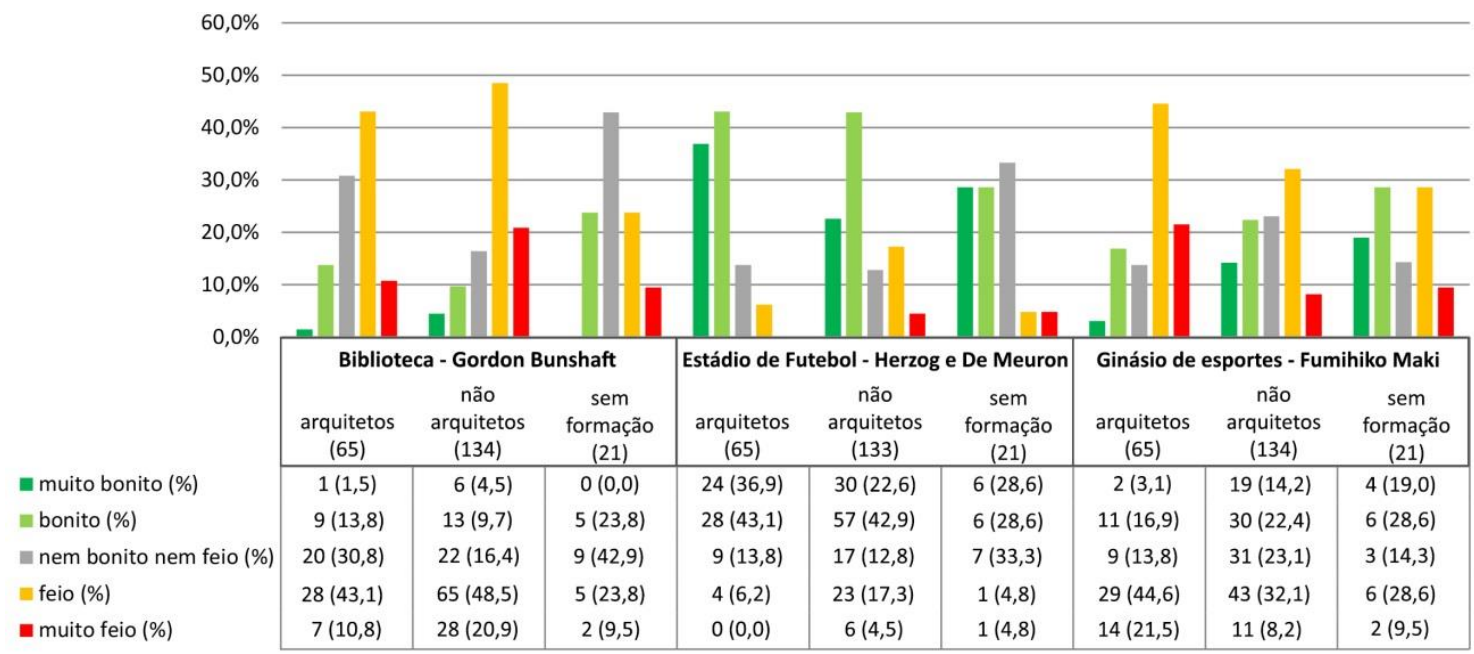

Este projeto também é o menos satisfatório e foi avaliado negativamente por 69,4\% (93 de 134). As diferenças nas avaliações dos projetos nesse segundo conjunto pelos não arquitetos com formação universitária são estatisticamente significativas (Kendall's W, teste estatístico $=98,662$, sig. $=0,000$ ), com essas avaliações estando em consonância com as preferências.

O projeto de Herzog e De Meuron (Figura 5) é o mais preferido por aqueles sem formação universitária (44,4\% - 8 de 18), basicamente em função da existência de estímulo visual $(7-87,5 \%)$, mas também da percepção por dois (25\%) respondentes da existência de falta de similaridade entre as formas. Esse projeto 
também é o mais satisfatório e foi avaliado positivamente pela maioria desses respondentes $(57,2 \%-12$ de 21; Figura 6). O projeto de Fumihiko Maki foi preferido por uma quantidade um pouco menor (33,3\% - 6 de 18) de respondentes sem formação universitária, devido à:

(a) existência de estímulo visual $(5-83,3 \%)$;

(b) falta de regularidade geométrica das formas (3-50\%);

(c) similaridade entre as formas $(2-33,3 \%)$;

(d) relação ordenada entre as formas $(2-33,3 \%)$; e

(e) relação desordenada entre as formas $(2-33,3 \%)$.

Esse projeto foi avaliado positivamente por 47,6\% (10 de 21) daqueles sem formação universitária. Os projetos de Gordon Bunshaft [em razão, primeiramente, da falta de estímulo visual (7 - 87,5\%), e, secundariamente, da relação ordenada entre as formas $(2-25 \%)$ e regularidade geométrica das formas $(2-$ $25 \%)$ ] e de Fumihiko Maki [devido à falta de similaridade entre as formas ( $3-37,5 \%)$, relação desordenada entre as formas $(3-37,5 \%)$ e falta de estímulo visual $(3-37,5 \%)]$ são os menos preferidos pela mesma quantidade desses respondentes $(44,4 \%-8$ de 18$)$. O projeto menos satisfatório é o de Gordon Bunshaft, que foi avaliado negativamente por $33,3 \%$ ( 7 de 21 ) e positivamente por apenas $23,8 \%$ ( 5 de 21 ) daqueles sem formação universitária, enquanto o projeto de Fumihiko Maki foi avaliado negativamente por $38,1 \%$ ( 8 de 21) e positivamente por 47,6\% (10 de 21). Embora em conformidade com as preferências, as diferentes avaliações dos projetos nesse segundo conjunto por aqueles sem formação não são sustentadas estatisticamente (Kendall's W).

Por sua vez, as diferenças entre as avaliações da biblioteca de Gordon Bunshaft, do estádio de futebol de Herzog e De Meuron e do ginásio de esportes de Fumihiko Maki (Figura 6) pelos três grupos de respondentes são sustentadas estatisticamente (teste Kruskal-Wallis, valores do teste estatístico e significância, respectivamente: 9,319 , sig. $=0,009 ; 7,953$, sig. $=0,019 ; 15,147$, sig. $=0,001)$. O projeto de Gordon Bunshaft foi mais bem avaliado por aqueles sem formação universitária (média dos valores ordinais obtida através do teste Kruskal-Wallis $=$ mvo $=139,02)$ e pior avaliado pelos não arquitetos com formação universitária $(m v o=101,48)$, diferença esta sustentada estatisticamente pelo teste de Dunn (teste estatístico padrão $=-2,660$, adj. sig. $=0,023$ ). Por outro lado, o projeto de Herzog e De Meuron foi mais bem avaliado pelos arquitetos $(\operatorname{mvo}=127,60)$ e pior avaliado pelos não arquitetos com formação universitária (mvo $=$ 102,15), sendo essa diferença estatisticamente significativa (teste de Dunn; teste estatístico padrão $=2,795$, adj. sig. $=0,016)$. Por sua vez, o projeto de Fumihiko Maki foi mais bem avaliado por aqueles sem formação universitária $(m v o=127,24)$ e pior avaliado pelos arquitetos $(\operatorname{mvo}=85,78)$. Essa diferença é confirmada estatisticamente pelo teste de Dunn (teste estatístico padrão $=-2,684$, adj. sig. $=0,022$ ), que também revela a existência de diferença estatisticamente significativa entre as avaliações dos arquitetos e dos não arquitetos (teste estatístico padrão $=-3,665$, adj. sig. $=0,001)$.

Considerando o conjunto 3 com os projetos de Kenzo Tange, I. M. Pei e Wang Shu (Figuras 7), o projeto de Wang Shu é, claramente, o mais preferido pelos arquitetos (80,7\% - 46 de 57), fundamentalmente devido à:

(a) relação ordenada entre as formas $(31-67,4 \%)$;

(b) regularidade geométrica das formas $(23-50 \%)$; e

(c) existência de estímulo visual $(14-30,4 \%)$.

Esse projeto também é o mais satisfatório e foi avaliado positivamente pela clara maioria dos arquitetos (75,9\% - 47 de 62; Figura 8). O menos preferido (47,7\% - 27 de 57) é o projeto de Kenzo Tange, devido à relação desordenada entre as formas $(13-48,1 \%)$, seguido de perto $(42,1 \%-24$ de 57$)$ pelo projeto de I. M. Pei, em função da relação desordenada entre as formas $(14-58,3 \%)$, da falta de similaridade entre as formas $(6-25 \%)$ e da falta de regularidade geométrica das formas $(6-25 \%)$. A avaliação do projeto de Kenzo Tange pelos arquitetos foi muito negativa (50\% - 32 de 64$)$ assim como foi a do projeto de I. M. Pei (33,9\% -22 de 65$)$.

As diferenças nas avaliações dos projetos nesse terceiro conjunto pelos arquitetos são confirmadas estatisticamente (Kendall's W, teste estatístico $=38,033$, sig. $=0,000$ ) e essas avaliações são consistentes com as preferências. 
Figura 7 - Preferências pelos projetos de Kenzo Tange, I. M. Pei e Wang Shu - conjunto 3

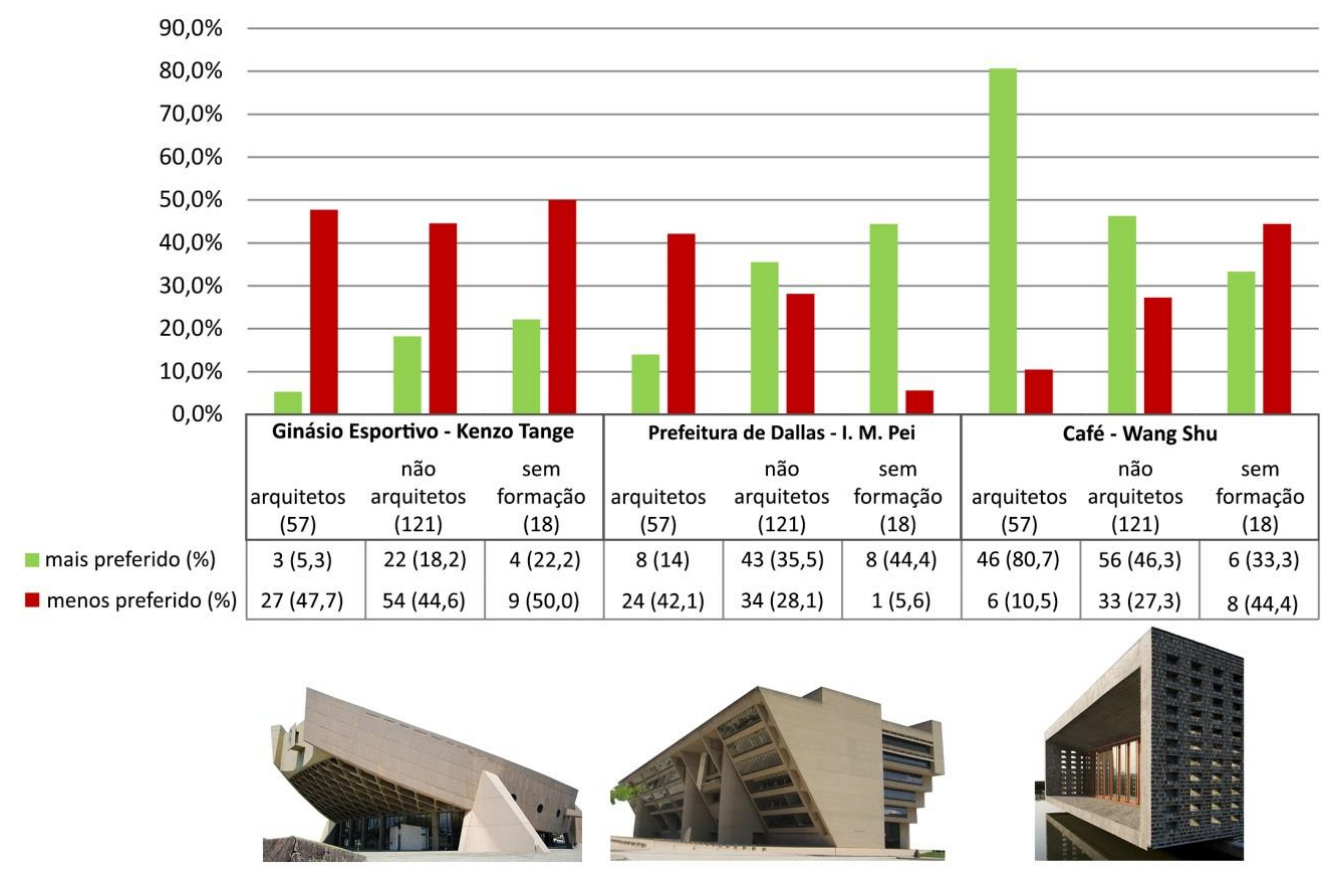

Fontes: 1 - Ginásio esportivo (1964), Takamatsu, Japão, Kenzo Tange (1987)

http: / / www.lifeonsundays.com/post/9622096842/kenzo-tange-kagawa-prefectural-gymnasium-japan; 2 - Prefeitura de Dallas (1978) - EUA, I. M. Pei (1983) http: / www.travelsupermarket.com/blog/12-more-sci-fi-film-locations-you-canactually-visit/; e 3 - Café (2006) Jinhua, China, Wang Shu (2012) http://www.pritzkerprize.com/media/2012_media/imagens-download.

Figura 8 - Avaliações individuais dos projetos de Kenzo Tange, I.M. Pei e Wang Shu - conjunto 3

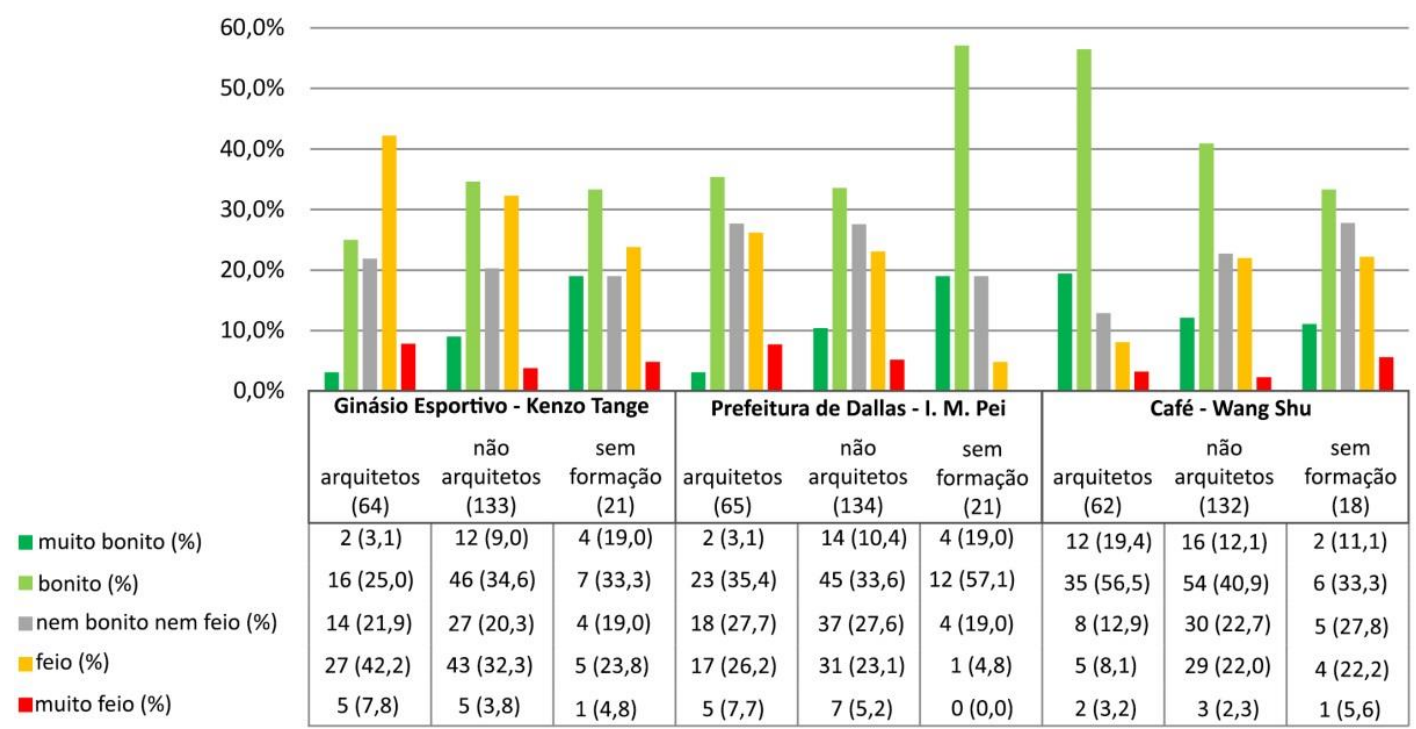

O projeto de Wang Shu também é o mais preferido pelos não arquitetos com formação universitária (46,3\% - 56 de 121; Figura 7), em função da:

(a) existência de estímulo visual $(30-53,6 \%)$;

(b) relação ordenada entre as formas (24 - 42,9\%);

(c) regularidade geométrica das formas $(20-35,7 \%)$; e

(d) da similaridade entre as formas $(18-32,1 \%)$. 
Esse projeto também é o mais satisfatório e foi avaliado positivamente pela maioria dos não arquitetos com formação universitária (52\% - 70 de 132; Figura 8).

O menos preferido $(44,6 \%$ - 54 de 121$)$ é o projeto de Kenzo Tange, devido à relação desordenada entre as formas $(19-35,2 \%)$. Esse projeto é o menos satisfatório e foi avaliado negativamente por 36,1\% (48 de 133) dos não arquitetos com formação universitária. As preferências são consistentes com as avaliações desses três projetos por esse grupo, mas as diferenças em tais avaliações não são sustentadas estatisticamente (teste Kendall's W).

Para aqueles sem formação universitária, o mais preferido $(44,4 \%-8$ de 18$)$ é o projeto de I. M. Pei (Figura $7)$, devido, principalmente, à existência de estímulo visual $(6-75 \%)$, e à relação ordenada entre as formas $(2$ - 25\%). Esse projeto é o mais satisfatório e foi avaliado positivamente pela clara maioria daqueles sem formação universitária $(76,1 \%$ - 16 de 21; Figura 8). O projeto de Wang Shu aparece logo depois na preferência $(33,3 \%$ - 6 de 18$)$ devido à existência de estímulo visual $(5-83,3 \%)$, similaridade entre as formas $(2-33,3 \%)$, e relação ordenada entre as formas $(2-33,3 \%)$, sendo avaliado positivamente por $44,4 \%$ (8 de 18) daqueles sem formação universitária. O menos preferido é o projeto de Kenzo Tange (50\% - 9 de 18) em razão da falta de estímulo visual $(8-88,9 \%)$, da falta de similaridade entre as formas $(2-$ $22,2 \%)$ e da relação desordenada entre as formas $(2-22,2 \%)$, seguido pelo projeto de Wang Shu $(44,4 \%-8$ de 18), devido à falta de estímulo visual (6-75\%), à similaridade entre as formas $(2-25 \%)$ e à regularidade geométrica das formas $(2-25 \%)$. O projeto de Kenzo Tange foi avaliado negativamente por $28,6 \%$ (6 de 21) e positivamente por $52,3 \%$ (11 de 21 ), enquanto a projeto de Wang Shu foi avaliado negativamente por $27,8 \%$ (5 de 18 ) e positivamente por $44,4 \%$ ( 8 de 18 ), o que indica que este foi um pouco pior avaliado que o projeto de Kenzo Tange e que houve uma inversão em relação aos projetos menos preferidos. Contudo, essas diferenças entre as avaliações desses três projetos por aqueles sem formação universitária não são corroboradas estatisticamente (teste Kendall's W).

Por sua vez, as diferenças entre as avaliações do ginásio esportivo por Kenzo Tange da Prefeitura de Dallas por I. M. Pei, e do café por Wang Shu (Figura 8) pelos três grupos de respondentes são sustentadas estatisticamente (teste Kruskal-Wallis, valores do teste estatístico e significância, respectivamente: 7,624, sig. $=0,022 ; 11,651$, sig. $=0,003 ; 9,399$, sig. = 0,009). O projeto de Kenzo Tange foi mais bem avaliado por aqueles sem formação universitária (média dos valores ordinais obtida através do teste Kruskal-Wallis = mvo $=127,95)$ e pior avaliado pelos arquitetos $(m v o=93,03)$. Contudo, conforme o teste de Dunn, essa diferença não é estatisticamente significativa. O projeto de I. M. Pei também foi mais bem avaliado por aqueles sem formação universitária $(\mathrm{mvo}=150,9)$ e pior avaliado pelos arquitetos $(\operatorname{mvo}=98,65)$. Segundo o teste de Dunn é confirmada a diferença estatisticamente significativa entre as avaliações desses dois grupos (teste estatístico padrão $=-3,409$, adj. sig. $=0,002$ ), assim como entre as avaliações dos não arquitetos e daqueles sem formação (teste estatístico padrão $=-2,859$, adj. sig. $=0,013$ ). Por outro lado, o projeto de Wang Shu foi mais bem avaliado pelos arquitetos $(m v o=125,12)$ e pior avaliado por aqueles sem formação universitária $(m v o=91,14)$. Entretanto, os resultados do teste Dunn revelam a existência de uma diferença estatisticamente significativa entre as avaliações dos arquitetos e dos não arquitetos (teste estatístico padrão $=2,832$, adj. sig. $=0,014$ ), embora a média dos valores ordinais (mvo) dos não arquitetos seja um pouco maior $(99,85)$ do que daqueles sem formação.

Considerando o conjunto 4, com os projetos de Jorn Utzon, Gordon Bunshaft e de Kenzo Tange (Figura 9), o projeto de Jorn Utzon é claramente o mais preferido pelos arquitetos ( $93 \%$ - 53 de 57), fundamentalmente devido à existência de estímulo visual $(37-69,8 \%)$, relação ordenada entre as formas $(27-50,9 \%)$, e similaridade entre as formas $(14-26,4 \%)$. Esse também é o projeto mais satisfatório e foi avaliado positivamente pela quase totalidade dos arquitetos $(96,8 \%-60$ de 62 ; Figura 10). O menos preferido pelos arquitetos (64,9\% - 37 de 57) é o projeto de Kenzo Tange (Figura 3), devido à relação desordenada entre as formas $(21-56,75 \%)$. Esse projeto também foi o pior avaliado, com uma avaliação muito negativa $(61,3 \%$ 38 de 62) pelos arquitetos. Essas diferenças entre as avaliações dos projetos nesse quarto conjunto pelos arquitetos são confirmadas estatisticamente (Kendall's W, teste estatístico $=78.319$, sig. $=0,000$ ) e essas avaliações estão em consonância com as preferências.

O projeto de Jorn Utzon (Figura 9) é visivelmente o mais preferido pelos não arquitetos com formação universitária $(73,1 \%$ - 87 de 119), basicamente devido à existência de estímulo visual (69 - 79,3\%), similaridade entre as formas $(27-31 \%)$ e relação ordenada entre as formas $(25-28,7 \%)$. Esse também é o projeto mais satisfatório e foi avaliado positivamente pela evidente maioria desses respondentes $(72 \%-95$ de 132; Figura 10). O menos preferido pela maioria dos não arquitetos com formação universitária $(55,5 \%$ 66 de 119) é o projeto de Kenzo Tange, devido à relação desordenada entre as formas $(31-46,96 \%)$ e à falta de estímulo visual $(18-27,27 \%)$. Esse projeto também é o menos satisfatório e foi avaliado 
negativamente por $62,9 \%$ (83 de 132) desses respondentes. Entretanto, para um percentual que não pode ser desprezado (38,7\% - 46 de 119) o projeto menos preferido é o de Gordon Bunshaft em função da falta de estímulo visual $(31-67,39 \%)$, da regularidade geométrica das formas $(17-36,95 \%)$ e da similaridade entre as formas $(14-30,43 \%)$. Ainda, esse projeto foi avaliado negativamente por $53 \%$ (71 de 134$)$ desses respondentes. Essas diferenças entre as avaliações dos projetos nesse quarto conjunto pelos não arquitetos com formação universitária são sustentadas estatisticamente (Kendall's W, teste estatístico $=111.485$, sig. $=$ 0,000), com tais avaliações estando em concordância com as preferências.

O projeto de Jorn Utzon (Figura 9) também é o mais preferido por aqueles sem formação universitária $(47,1 \%-8$ de 17$)$, em função da:

(a) existência de estímulo visual $(7-87,5 \%)$;

(b) similaridade entre as formas (3 - 37,5\%);

(c) regularidade geométrica das formas $(3-37,5 \%)$;

(d) relação ordenada entre as formas $(2-25 \%)$; e

(e) relação desordenada entre as formas $(2-25 \%)$.

O projeto de Jorn Utzon também é o mais satisfatório e foi avaliado positivamente pela clara maioria desses respondentes (73,7\% - 14 de 19; Figura 10). Logo a seguir está a preferência pelo projeto de Kenzo Tange (41,2\% - 7 de 17), basicamente devido à existência de estímulo visual ( $5-71,4 \%)$, projeto esse que foi avaliado positivamente por $40 \%$ ( 8 de 20 ) daqueles sem formação universitária. O projeto de Gordon Bunshaft é o menos preferido pela maioria desses respondentes $(52,9 \%$ - 9 de 17$)$, devido à falta de estímulo visual $(8-88,88 \%)$ e à regularidade geométrica das formas $(3-33,33 \%)$. Esse projeto também foi avaliado negativamente por 33,4\% (7 de 21) e positivamente por 28,6\% (6 de 21) daqueles sem formação universitária. Por sua vez, embora o projeto de Kenzo Tange tenha sido o menos preferido por uma quantidade bem menor de respondentes nesse grupo (29,5\% - 5 de 17), em função da relação desordenada entre as formas $(3-60 \%)$, ele foi avaliado negativamente por 50\% (10 de 20$)$ desses respondentes e positivamente por $40 \%$ ( 8 de 20 ), o que revela que tal projeto foi o pior avaliado. Contudo, essas diferenças entre as avaliações dos projetos nesse quarto conjunto por aqueles sem formação universitária não são sustentadas estatisticamente (Kendall's W), embora essas avaliações estejam em sintonia com as preferências.

Figura 9 - Preferências pelos projetos de Jorn Utzon, Gordon Bunshaft e Kenzo Tange - conjunto 4

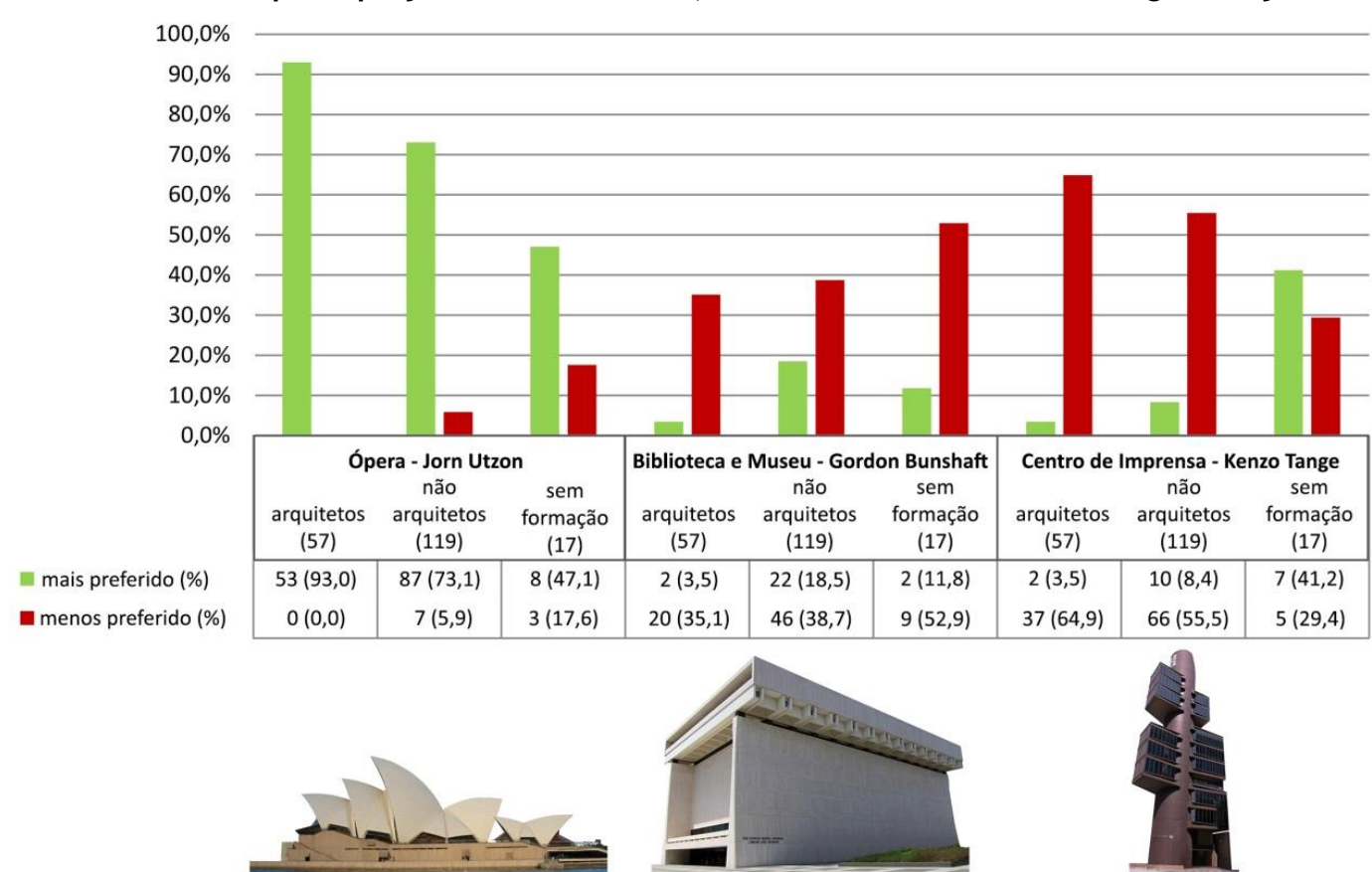

Fontes: 1 - Ópera de Sydney (1973), Austrália, Jorn Utzon (2003) - Autor (2002); 2 - Biblioteca e museu (1971), Austin, EUA, Gordon Bunshaft (1988) http://www.flickr.com/photos/wallyg/8035778427/; e 3 - Centro de imprensa (1967), Chuo, Japão, Kenzo Tange (1987) http://architecturalmoleskine.blogspot.com.br/2011/10/metabolist-movement.html. 
Figura 10 - Avaliações individuais dos projetos de Jorn Utzon, Gordon Bunshaft e Kenzo Tange conjunto 4

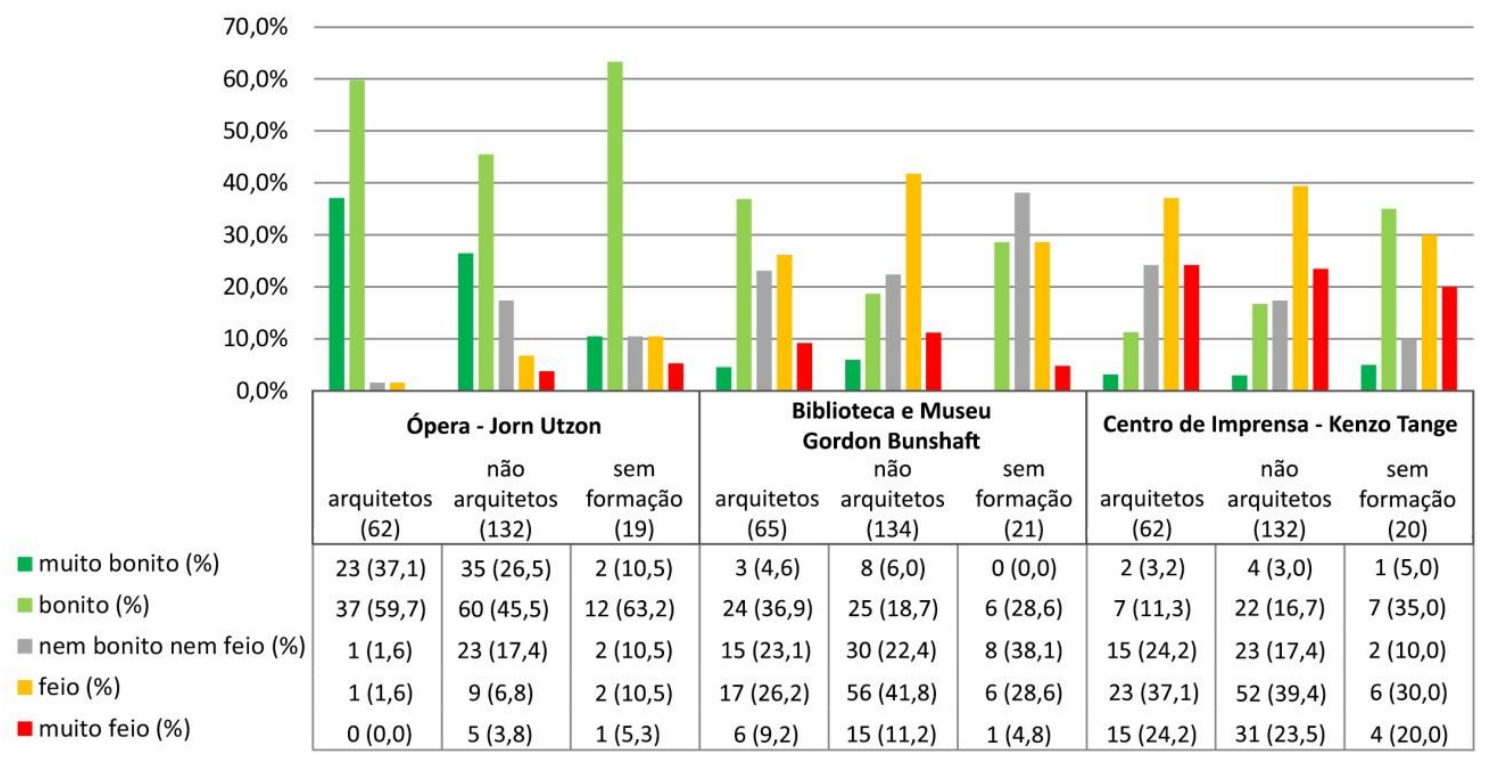

Por sua vez, as diferenças entre as avaliações da ópera por Jorn Utzon pelos três grupos de respondentes são sustentadas estatisticamente (teste Kruskal-Wallis, teste estatístico $=12,850$, sig. $=0,002$ ). Esse projeto foi mais bem avaliado pelos arquitetos (média dos valores ordinais obtida através do teste Kruskal-Wallis = mvo $=127.86)$ e pior avaliado por aqueles sem formação universitária $(m v o=86.66)$. Essa diferença é sustentada estatisticamente pelo teste de Dunn (teste estatístico padrão $=2,779$, adj. sig. $=0,016$ ), assim como a diferença entre as avaliações dos arquitetos e dos não arquitetos (teste estatístico padrão $=3,186$, adj. sig. $=0,004)$.

Embora as diferenças entre as avaliações da biblioteca e do museu por Gordon Bunshaft e do centro de imprensa por Kenzo Tange pelos três grupos de respondentes não tenham sustentação estatística (teste Kruskal-Wallis), esses projetos foram avaliados conforme segue: o projeto por Gordon Bunshaft foi mais bem avaliado pelos arquitetos $(\operatorname{mvo}=123,94)$ e pior avaliado pelos não arquitetos com formação universitária $(\mathrm{mvo}=102,65)$; por sua vez, o projeto por Kenzo Tange foi mais bem avaliado por aqueles sem formação universitária $(m v o=124.42)$ e pior avaliado pelos arquitetos (104.78).

\section{Conclusões}

Os projetos preferidos pelos arquitetos em comparação aos outros dois projetos em cada um dos quatro conjuntos, assim como os projetos mais bem avaliados individualmente em cada um desses conjuntos e com avaliações muito positivas ou positivas, são os projetos de Álvaro Siza (conjunto 1), Herzog e De Meuron (conjunto 2), Wang Shu (conjunto 3) e Jorn Utzon (conjunto 4). Tais resultados decorrem fundamentalmente em função da existência de estímulo visual seguida pela relação ordenada entre as formas, com esta aparecendo como a principal justificativa para a preferência pelo projeto de Wang Shu, seguida pela regularidade geométrica das formas e pela existência de estímulo visual. Por sua vez, os projetos menos preferidos pelos arquitetos em comparação aos outros dois projetos em cada um dos quatro conjuntos, assim como os projetos pior avaliados individualmente em cada conjunto e com avaliações muito negativas, são os projetos de Jean Nouvel (conjunto 1), Fumihiko Maki (conjunto 2), e os dois projetos de Kenzo Tange (conjuntos 3 e 4), fundamentalmente em função da relação desordenada entre as formas, embora também houvesse a percepção de excesso de estímulos e de cores no projeto de Jean Nouvel. Outros projetos com avaliações muito negativas pelos arquitetos e que foram menos preferidos em segundo lugar são os projetos de Aldo Rossi (conjunto 1), basicamente devido à falta de estímulo visual, e de I. M. Pei (conjunto 3), sobretudo em função da relação desordenada entre as formas. O fato de existirem diferenças, confirmadas estatisticamente, entre as avaliações dos projetos em cada um dos quatro conjuntos e que tais avaliações são consistentes com as preferências evidencia que diferentes atributos formais de projetos de arquitetos premiados com o Pritzker foram percebidos distintamente pelo grupo dos arquitetos. Ainda, essas avaliações 
estão em sintonia com a categorização prévia dos 12 projetos realizada pelo pesquisador arquiteto e por estudantes de arquitetura.

Os projetos preferidos pelos não arquitetos com formação universitária em comparação aos outros dois projetos em cada um dos quatro conjuntos, assim como os projetos mais bem avaliados individualmente em cada conjunto e com avaliações positivas pela maioria dos respondentes, são os projetos de Álvaro Siza, Herzog e De Meuron, Wang Shu, e Jorn Utzon, primeiramente devido à existência de estímulo visual (em todos os projetos), e, adicionalmente, em razão da relação ordenada entre as formas (em todos os projetos, exceto o de Herzog e De Meuron), similaridade entre as formas (projetos de Wang Shu e Jorn Utzon) e regularidade geométrica das formas (projetos de Álvaro Siza e Wang Shu). Ainda, alguns perceberam a existência de relação desordenada entre as formas no projeto de Herzog e De Meuron. Por sua vez, os projetos menos preferidos pelos não arquitetos com formação universitária em comparação aos outros dois projetos em cada um dos quatro conjuntos, assim como os projetos pior avaliados individualmente em cada conjunto e com avaliações muito negativas, são os projetos de Aldo Rossi, Gordon Bunshaft, e os dois projetos de Kenzo Tange, primeiramente em função da falta de estímulo visual (projetos de Aldo Rossi e de Gordon Bunshaft) e da relação desordenada entre as formas (projetos de Kenzo Tange). A menor preferência pelo Centro de Imprensa de Kenzo Tange foi seguida de perto pela menor preferência pelo projeto de Gordon Bunshaft, também com uma avaliação muito negativa, em função da falta de estímulo visual, da regularidade geométrica das formas e da similaridade entre elas. $O$ fato de existirem diferenças, corroboradas estatisticamente, entre as avaliações dos projetos em cada um dos quatro conjuntos e que tais avaliações são consistentes com as preferências, com exceção das diferenças em um conjunto (projetos de Kenzo Tange, I. M. Pei, e de Wang Shu), tende a demonstrar que distintas características formais de projetos de arquitetos premiados com o Pritzker foram percebidas distintamente pelo grupo dos não arquitetos com formação universitária.

Os projetos preferidos por aqueles sem formação universitária em comparação aos outros dois projetos em cada um dos quatro conjuntos, assim como os projetos mais bem avaliados individualmente em cada conjunto e com avaliações positivas pela maioria dos respondentes, são os projetos de Álvaro Siza, Herzog e De Meuron, I. M. Pei, e Jorn Utzon, primeiramente devido à existência de estímulo visual, indicada em todos os projetos, mais do que o dobro de vezes do que cada uma das demais razões. Em seus respectivos conjuntos esses quatro projetos foram seguidos de perto pela preferência, respectivamente, pelos projetos de Jean Nouvel, Fumihiko Maki, Wang Shu e Kenzo Tange, em razão, basicamente, da existência de estímulo visual, bem mais indicada em todos os projetos do que as outras razões. Por sua vez, os projetos menos preferidos por aqueles sem formação universitária em comparação aos outros dois projetos em cada um dos quatro conjuntos, assim como os projetos que tendem a ser pior avaliados individualmente em cada conjunto e com avaliações muito negativas, são os projetos de Aldo Rossi, Gordon Bunshaft (pior avaliado) e Fumihiko Maki igualmente (no conjunto 2), Kenzo Tange (avaliação negativa, enquanto a do projeto de Wang Shu é muito negativa), e Gordon Bunshaft (conjunto 4), primeiramente em função da falta de estímulo visual (juntamente com falta de similaridade entre as formas, e da relação desordenada entre as formas (projeto de Fumihiko Maki). Os projetos menos preferidos nos conjuntos 3 e 4 foram seguidos de perto pela menor preferência, respectivamente, pelos projetos de Wang Shu (em razão, basicamente, da falta de estímulo visual), e de Kenzo Tange, devido à relação desordenada entre as formas. As avaliações tendem a ser consistentes com as preferências, mas o fato de haver suporte estatístico somente para as diferenças entre as avaliações dos projetos de Álvaro Siza, Jean Nouvel e Aldo Rossi indica que distintas características formais de projetos de arquitetos premiados com o Pritzker tendem a não ser percebidas com muita clareza por aqueles sem formação universitária.

Logo, as características formais das composições arquitetônicas afetaram bem mais as avaliações daqueles com formação universitária, o que indica que amostras constituídas por esse grupo podem ser consideradas em novos estudos envolvendo avaliações estéticas de edificações. Essa indicação também se sustenta no fato de que neste estudo, assim como em outros (REIS; BIAVATTI; PEREIRA, 2014; REIS; PANZENHAGEN; GERSON, 2019), a amostra daqueles sem formação universitária foi bem menor do que as amostras daqueles com formação universitária (arquitetos e não arquitetos) obtidas através de questionários respondidos via internet. Adicionalmente, conforme evidenciado pelos resultados desta e de outras pesquisas (REIS; PANZENHAGEN; GERSON, 2019), aqueles com formação universitária, principalmente arquitetos, tendem a ter maior rigor em suas avaliações estéticas do que aqueles sem tal formação, o que sugere que edificações e conjuntos de edificações bem avaliados por aqueles com formação tenderiam também a ser bem avaliados por aqueles sem formação universitária, reduzindo ou eliminando a necessidade de amostra constituída por esse grupo. 
Embora existam diferenças estatisticamente significativas entre as avaliações de 9 dos 12 projetos pelos três grupos de respondentes, os projetos preferidos pelos arquitetos e pelos não arquitetos com formação universitária são os mesmos (Álvaro Siza, Herzog e De Meuron, Wang Shu e Jorn Utzon) e quase os mesmos por aqueles sem formação universitária que preferiram o projeto de I. M. Pei em lugar do projeto de Wang Shu. Ainda, as justificativas apresentadas para essas preferências pelos 12 projetos revelam que enquanto os três grupos indicaram a existência de estímulo visual, esta é indicada de forma bem mais intensa em todos os projetos (mais do que o dobro de vezes da segunda justificativa) por aqueles sem formação universitária. Por sua vez, a ideia de ordem também tende a fazer parte das explicações, principalmente dos arquitetos, que a incluíram em todas as suas justificativas (sendo a principal na preferência por um dos projetos - Wang Shu), enquanto esta não faz parte das justificativas pela preferência por um dos projetos (Herzog e De Meuron) pelos outros dois grupos. Logo, esses resultados evidenciam que as diferenças entre as preferências pelos três grupos com distintos níveis e tipos de formação acadêmica tende a estar mais na intensidade na menção das ideias de ordem e estímulo do que na desconsideração dessas ideias por algum grupo, não corroborando as diferenças mencionadas por Fawcett, Ellingham e Platt (2008) entre as preferências de arquitetos e leigos com formação por edificações com diferentes estilos. Portanto, os resultados obtidos corroboram aqueles de outros estudos sobre as preferências estéticas de edificações individuais (REIS; BIAVATTI; PEREIRA, 2014) e de conjuntos de edificações (REIS; BIAVATTI; PEREIRA, 2011), onde a presença simultânea de ordem e estímulo tende a gerar reações estéticas positivas por parte dos três grupos, embora os arquitetos valorizem mais a ideia de ordem e os não arquitetos (principalmente aqueles sem formação universitária) deem mais valor para o estímulo visual. Assim, os resultados apresentados também estão em sintonia com aqueles revelados em 2001 por Janssens (em Gjerde (2015)) de que os arquitetos geralmente preferem esquemas de cores com níveis mais altos de unidade e coerência (maior ênfase na ordem), enquanto os leigos preferem aqueles com maior complexidade e variação (maior ênfase no estímulo).

Em síntese, este estudo evidencia que as distintas formações de arquitetos e leigos, que poderiam explicar diferenças entre as suas avaliações estéticas, conforme citado por Gifford et al. (2000), não foram suficientes para gerar diferenças significativas entre as avaliações dos projetos de arquitetos premiados com o Pritzker pelos três grupos com distintos níveis e tipos de formação acadêmica e que os projetos mais preferidos, por qualquer um dos grupos, tende a ser caracterizado pela presença de ordem e de estímulo.

Esses resultados sobre a importância da existência de ordem e estímulo na composição arquitetônica são corroborados por estudos recentes envolvendo rastreamento ocular que evidenciam que as pessoas procuram por "[...] detalhes, contrastes e, o mais importante, estruturas que podem ser prontamente identificadas e compreendidas [...]" conforme salientado por Lavdas e Schirpke (2020, p. 11). Nesse sentido, os resultados de um estudo realizado por esses autores (LAVDAS; SCHIRPKE, 2020) também evidenciam que cenas com edificações com alto grau de complexidade (e, logo, de estímulo) e organização são preferíveis e consideradas mais bonitas do que cenas onde as edificações não possuem tais características. Os resultados obtidos no presente estudo também estão em sintonia com a definição de beleza pela Gestalt como "ordem na complexidade" e à formulação por Eysenck, como resultado de seu trabalho na área da estética empírica, do valor estético ser equivalente ao produto da ordem pela complexidade no objeto observado e, por outro lado, em oposição à ideia de que a beleza está nos olhos de quem vê (MYSZKOWSKI; STORME; ZENASNI, 2016).

Adicionalmente, as razões para as preferências corroboram outros resultados (REIS; BIAVATTI; PEREIRA, 2011, 2014) que mostram a relevância, para os três grupos (com distintos níveis e tipos de formação) dos atributos formais das edificações em contraposição aos aspectos simbólicos. Essas razões também estão em consonância com a asserção de que as respostas estéticas daqueles com formação em desenho estão baseadas em suas percepções da composição (RAPOPORT, 1982), com base no argumento de que o componente estético da percepção visual é determinado pelo estímulo gerado pela forma e não pelo seu conteúdo semântico (REDIES, 2007) e, logo, apresentam discrepância em relação à sugestão de que os leigos avaliam o meio ambiente fundamentalmente pelos seus significados (RAPOPORT, 1982). Também coincidem com os resultados acerca da relevância dos aspectos formais, em detrimento dos simbólicos, as explicações para as avaliações muito positivas da aparência do Museu do Louvre com a Pirâmide, tanto por brasileiros quanto por franceses com distintos níveis e tipos de formação, constituídas pelos atributos formais da Pirâmide e do antigo Museu e pelas relações entre tais atributos, e não por associações a tais atributos e relações, mesmo nas explicações dos leigos (REIS; SOUZA, 2016).

Por sua vez, os projetos menos preferidos pelos arquitetos (aqueles de Jean Nouvel, Fumihiko Maki e os dois projetos de Kenzo Tange) diferem em 50\% daqueles menos preferidos pelos não arquitetos com 
formação universitária (projetos de Aldo Rossi, Gordon Bunshaft e os dois projetos de Kenzo Tange) e em $50 \%$ dos menos preferidos por aqueles sem formação universitária (projetos de Aldo Rossi; Gordon Bunshaft e Fumihiko Maki; Kenzo Tange; Gordon Bunshaft), enquanto a diferença é menor (25\%) entre os projetos menos preferidos por esses dois grupos de não arquitetos. As razões para os projetos menos preferidos sustentam aqueles de pesquisas (REIS; BIAVATTI; PEREIRA, 2011, 2014) que revelam como principal explicação para a menor preferência pela aparência de uma edificação por parte dos arquitetos, a falta de ordem e, por parte daqueles sem formação universitária, a falta de estímulo visual. Assim, a relação desordenada entre as formas é, fundamentalmente, a justificativa indicada pelos arquitetos para os quatro projetos menos preferidos, enquanto os não arquitetos com formação universitária justificam, primeiramente, em função da falta de estímulo visual (projetos de Aldo Rossi e de Gordon Bunshaft) e da relação desordenada entre as formas (projetos de Kenzo Tange), e aqueles sem formação universitária essencialmente mencionam a falta de estímulo visual (juntamente com falta de similaridade entre as formas e relação desordenada entre as formas, no caso do projeto de Fumihiko Maki) como razões para os projetos menos preferidos. Essas preferências e justificativas condizem com o fato que, dentre os 9 projetos com diferenças significativas entre as avaliações pelos três grupos, os arquitetos tendem a avaliar melhor aqueles com a clara presença de ordem (de autoria de Álvaro Siza, Aldo Rossi, Herzog e De Meuron, Wang Shu e Jorn Utzon) enquanto as pessoas sem formação universitária tendem a avaliar melhor os demais projetos (de autoria de Jean Nouvel, Gordon Bunshaft - conjunto 2, Fumihiko Maki, e I. M. Pei) que se caracterizam pela presença bem menor da ideia de ordem e foram pior avaliados pelos arquitetos, exceto a biblioteca por Gordon Bunshaft, onde a ideia de ordem é visível.

Este estudo evidencia, portanto, que os projetos de arquitetos que receberam o maior prêmio de arquitetura existente no mundo são percebidos e avaliados diferentemente pelos três grupos em função, fundamentalmente de suas relações formais que revelam claras diferenças nos níveis de ordem e de estímulo visual. Somadas às evidências geradas em outros estudos (REIS; BIAVATTI; PEREIRA, 2011, 2014), os resultados desta pesquisa enfatizam a importância da compreensão das relações formais para a concepção de uma composição arquitetônica satisfatória e, logo, a relevância da incorporação desse conhecimento no ensino da arquitetura assim como nas próprias avaliações estéticas de projetos arquitetônicos, incluindo aqueles de candidatos ao Prêmio Pritzker. Portanto, tais evidências não corroboram o pressuposto da abordagem da estética filosófica de que "a beleza está nos olhos de quem vê" (LANG, 1987; REIS; BIAVATTI; PEREIRA, 2011) e, logo, que a avaliação e a elaboração de uma composição arquitetônica possam estar baseadas, simplesmente, em gostos pessoais e/ou associações simbólicas. Concluindo, os resultados obtidos na análise da percepção estética da composição arquitetônica dos doze projetos de arquitetos premiados com o Pritzker contribuem para o conhecimento existente sobre a estética da arquitetura, especificamente sobre a estética formal e as razões para as percepções e avaliações estéticas de composições arquitetônicas. Como limitação desta pesquisa pode ser mencionada a pequena amostra daqueles sem formação universitária, embora tenha sido fundamentada a perda de importância da participação desse grupo em avaliações estéticas de edificações. Ainda, podem ser sugeridas novas pesquisas envolvendo a avaliação estética e a preferência por outros projetos de arquitetos contemplados com o Prêmio Pritzker através de arquitetos e de pessoas com curso universitário que não envolva formação em estética.

\section{Referências}

FAWCETT, W.; ELLINGHAM, I.; PLATT, S. Reconciling the architectural preferences of architects and the public: the ordered preference model. Environment and Behavior, London, v. 40, n. 5, p. 599-618, 2008.

GIFFORD, R. et al. Decoding modern architecture: a Lens Model approach for understanding the aesthetic differences of architects and laypersons. Environment and Behavior, London, v. 32, n. 2, p. 163-187, mar. 2000 .

GJERDE, M. T. Street perceptions: a study of visual preferences for New Zealand streetscapes.

Wellington, 2015. $405 \mathrm{f}$. PhD thesis, Victoria University of Wellington, Wellington, New Zealand, 2015.

GREGOLETTO, D. Edifícios altos na cidade média de Caxias do Sul: efeitos na estética urbana, nos usos de espaços abertos e na satisfação residencial. Porto Alegre, 2019. 553 f. Tese (Doutorado em Planejamento Urbano e Regional) - Programa de Pós-Graduação em Planejamento Urbano e Regional, Universidade Federal do Rio Grande do Sul, Porto Alegre, 2019. 
HASSE, C.; WEBER, R. Visual balance of facades: investigating the interplay between eye movements and balance judgments. In: INTERNATIONAL ASSOCIATION OF EMPIRICAL AESTHETICS CONGRESS, 21., Dresden, 2010. Proceedings [...] Dresden: IAEA, 2010.

JEFFREY, D.; REYNOLDS, G. Planners, architects, the public, and aesthetics factor analysis of preferences for infill developments. Journal of Architectural and Planning Research, Chicago, v. 16, n. 4, p. 271 288, 1999.

LANG, J. Creating architectural theory: the role of the behavioural sciences in environmental design. New York: Van Nostrand Reinhold, 1987.

LAVDAS, A. A.; SCHIRPKE, U. Aesthetic preference is related to organized complexity. PLOS ONE, São Francisco, v. 15, n. 6, p. 1-15, 2020.

LAY, M. C.; REIS, A. Análise quantitativa na área de estudos Ambiente-Comportamento. Ambiente Construído, Porto Alegre, v. 5, n. 2, p. 21-36, abr./jun. 2005.

MAHDAVINEJAD, M.; HOSSEINI, S. A. Data mining and content analysis of the jury citations of the Pritzker Architecture Prize (1977-2017). Journal of Architecture and Urbanism, Vilnius, v. 43, n. 1, p. 71-90, 2019.

MYSZKOWSKI, N.; STORME, M.; ZENASNI, F. Order in complexity: how Hans Eysenck brought differential psychology and aesthetics together. Personality and Individual Differences, Amsterdam, v.103, p.156-162, 2016.

NASAR, J. L. Urban design aesthetics: the evaluative qualities of building exteriors. Environment and Behavior, London, v. 26, p. 377-401, 1994.

PORTEOUS, J. D. Environmental Aesthetics: ideas, politics and planning. London: Routledge, 1996.

RAPOPORT, A. The meaning of the built environment: a nonverbal communication approach. Beverly Hills; London: Sage, 1982.

REDIES, C. A universal model of esthetic perception based on the sensory coding of natural stimuli. Spatial Vision, Leiden, v. 21, p. 97-117, 2007.

REIS, A. T.; PANZENHAGEN, A. F.; GERSON, V. L. Avaliações estéticas de interfaces com distintos níveis de permeabilidade e proximidade com os espaços abertos públicos. Ambiente Construído, Porto Alegre, v. 19, n. 3, p. 259-274, jul./set. 2019.

REIS, A.; BIAVATTI, C.; PEREIRA, M. L. Estética urbana: uma análise através das ideias de ordem, estímulo visual, valor histórico e familiaridade. Ambiente Construído, Porto Alegre, v. 11, n. 4, p. 185-204, out./dez. 2011.

REIS, A.; BIAVATTI, C.; PEREIRA, M. L. Composição arquitetônica e qualidade estética. Ambiente Construído, Porto Alegre, v. 14, n. 1, p. 191-213, jan./mar. 2014.

REIS, A.; LAY, M.C. Avaliação da qualidade de projetos: uma abordagem perceptiva e cognitiva.

Ambiente Construído, Porto Alegre, v. 6, n. 3, p. 21-34, jul./set. 2006.

REIS, A. T.; SOUZA, G. N. O projeto do 'Le Grand Louvre': uma análise estética e de usos.

Arquiteturarevista, São Leopoldo, v. 12, n. 2, p. 140-153, jul./dez. 2016.

SANOFF, H. Visual research methods in design. New York: Van Nostrand Reinhold, 1991.

THE HyatT foundation. The Pritzker Architecture Prize. Chicago: The Hyatt Foundation, 2018. Disponível em: https://www.pritzkerprize.com. Acesso em: 3 jan. 2018.

WEBER, R. On the Aesthetics of architecture: a Psychological Approach to the Structure and the Order of Perceived Architectural Space. Aldershot: Avebury, 1995.

\section{Agradecimentos}

Esta pesquisa foi realizada com bolsas de iniciação científica do Conselho Nacional de Desenvolvimento Científico e Tecnológico (CNPq), instituição governamental brasileira de fomento ao desenvolvimento científico e tecnológico. Além disso, agradecemos aos seguintes bolsistas de graduação em arquitetura e iniciação científica pela participação nesta pesquisa: Júnia Graziela Neumann, Isadora Martinez Diniz e Gabriel Marques. 


\section{Antônio Tarcísio da Luz Reis}

Departamento de Arquitetura, Faculdade de Arquitetura | Universidade Federal do Rio Grande do Sul | Rua Sarmento Leite, 320, 5 andar, sala 510, Centro | Porto Alegre - RS | CEP 90050-170 | Tel.: (51) 992155810 | E-mail: tarcisio@orion.ufrgs.br

\section{Ambiente Construído}

Revista da Associação Nacional de Tecnologia do Ambiente Construído Av. Osvaldo Aranha, $99-3^{\circ}$ andar, Centro

Porto Alegre - RS - Brasil

$$
\text { CEP 90035-190 }
$$

Telefone: +55 (51) 3308-4084

www.seer.ufrgs.br/ambienteconstruido www.scielo.br/ac

E-mail: ambienteconstruido@ufrgs.br

This is an open-access article distributed under the terms of the Creative Commons Attribution License. 